УДК 34.01

DOI 10.18413/2712-746X-2020-44-3-565-571

\title{
Отличие приказа от иных правовых актов органов исполнительной власти
}

\author{
Чернышов А.B. \\ Саратовская государственная юридическая академия, \\ 410056, Россия, г. Саратов, ул. Вольская, дом 1 \\ E-mail: d.grachev@lenta.ru
}

\begin{abstract}
Аннотация. Необходимо детальное разграничение правовых актов органов исполнительной власти, в обязанности которых входит издание приказов, постановлений, правил, инструкций и положений, а также распоряжений, так как каждому из актов свойственны свои признаки и основания для их принятия. Поскольку отсутствуют комплексные исследования данного вопроса, автором представлен анализ различных форм правовых актов органов исполнительной власти, среди которых постановления, распоряжения, правила, инструкции и положения. Выявлены характерные черты каждой из форм правовых актов. Так, специфика постановления проявляется в коллегиальном характере его принятия; правила и инструкции издаются в целях разъяснения реализации норм вышестоящего документа в части выполнения определенных действий, операции; принятие положений проводится в целях детальной регламентации правового статуса организаций и предприятий. Установлено, что приказ и распоряжение, в отличие от иных видов актов, являются достаточно похожими категориями, однако различия все-таки имеются: иерархичность и служебный характер приказа. Сделан вывод о необходимости разработки понятийного аппарата рассматриваемых актов и требований к их принятию.
\end{abstract}

Ключевые слова: правовые акты, постановление, приказ, распоряжение, правила, инструкция, положение, органы исполнительной власти.

Для цитирования: Чернышов А.В. 2020. Отличие приказа от иных правовых актов органов исполнительной власти. NOMOTHETIKA: Философия. Социология. Право. 45 (3): 565-571. DOI 10.18413/2712-746X-2020-44-3-565-571

\section{Difference of order from other legal acts executive authorities}

\author{
Andrey V. Chernyshov \\ Saratov State Law Academy \\ 1 Volskaya St, 410056, Saratov, Russia \\ E-mail: d.grachev@lenta.ru
}

\begin{abstract}
It is necessary to make a detailed distinction between the legal acts of the Executive authorities that are responsible for issuing orders, regulations, rules, instructions and regulations, as well as orders, since each of the acts has its own characteristics and grounds for their adoption. Since there are no comprehensive studies of this issue, the author presents an analysis of various forms of legal acts of Executive authorities, including resolutions, orders, rules, instructions and regulations. The characteristic features of each of the forms of legal acts are revealed. So, the specifics of the resolution is evident in the collegial nature of decision; the rules and regulations are issued to clarify the implementation of the superior instrument, perform a specific action, operation; the acceptance of the terms is held to detailed regulation of legal status of organizations and enterprises. It is established that the order and the order, unlike other types of acts, are quite similar categories, but there are still differences: the hierarchy and the
\end{abstract}


official nature of the order. It is concluded that it is necessary to develop the conceptual apparatus of the acts under consideration and the requirements for their adoption.

Key words: legal acts, resolutions, orders, orders, rules, instructions, regulations, Executive authorities.

For citation: Chernyshov A.V. 2020. Difference of order from other legal acts executive authorities. NOMOTHETIKA: Philosophy. Sociology. Law series. 45 (3): 565-571 (in Russian). DOI 10.18413/2712-746X-2020-44-3-565-571

\section{Введение}

Органы исполнительной власти, выполняющие функции по государственному управлению страной, наделены достаточно широкими полномочиями в сфере управления государственными делами. Одной из форм проявления их деятельности выступает разработка и издание правовых актов, которые представляют собой наиболее объемный и разнообразный вид нормативных правовых актов.

На законодательном уровне закреплено, что правовые акты издаются в виде постановлений, приказов, распоряжений, правил, инструкций и положений ${ }^{1}$. Однако в нем отсутствуют понятия указанных дефиниций, не выделены их характерные особенности, что ведет к многозначности толкования и применения. Вместе с тем указанные виды актов не равнозначны друг другу, они имеют ряд отличительных признаков, которые выражаются не только в своем содержании, но и на практике использования.

В рамках теории права, как и других отраслей, нет комплексных исследований по рассматриваемой теме. Ряд работ посвящены лишь отдельным вопросам, связанными с приказами и иными правовыми актами органов исполнительной власти. В этой связи в качестве цели нашего исследования выступает систематизация имеющихся знаний в отношении приказа и иных правовых актов органов исполнительной власти, а также выявление их характерных особенностей.

Итак, рассмотрим каждый из них.

\section{Приказ в системе правовых актов}

Особое значение среди правовых актов управления уделяется приказу. Являясь одной из форм выражения воли должностных лиц, он представляет собой первостепенный инструмент решения ежедневно возникающих вопросов в государственном управлении. По своей сути приказ представляет собой распорядительный акт, который издается исполнительными органами власти по распоряжению вышестоящего руководства или по личной инициативе для устранения неурегулированных вопросов в сфере государственного управления [Ваньков, 2018; Талаев, 2019].

В справочной литературе приказ определяется как официальное распоряжение, предписание органа власти; акт руководителя органа государственного управления, государственного учреждения, содержащий обязательные для определенного круга лиц установки [Кузнецов, 1998].

Дефиниция «приказ» закреплена и в Уставе внутренней службы Вооруженных Сил Российской Федерации, где под ним понимают распоряжение командира (начальника), обращенное к подчиненным и требующее обязательного выполнения определенных действий, соблюдения тех или иных правил или устанавливающее какой-либо порядок, по-

${ }^{1}$ Постановление Правительства РФ от 13.08.1997 № 1009 «Об утверждении Правил подготовки нормативных правовых актов федеральных органов исполнительной власти и их государственной регистрации» (ред. от 12.10.2019). Российская газета. 1997, 21 августа; С3 РФ. 2019. № 42 (часть III). Ст. 5912. 
ложение ${ }^{1}$. Кроме того, в документе установлено, что приказы издаются на правах единоначалия командиром и могут выражаться в письменной и устной форме, где письменный приказ приравнивается к нормативному акту.

Специфической чертой приказа выступает то, что большая часть приказов федеральных органов исполнительной власти содержит в себе и нормативные, и индивидуальные предписания [Вдовин, Гибадуллина, 2018]. В доктрине их обозначают смешанными правовыми актами, которые издаются при необходимости одновременного использования нескольких актов, в которых есть нормы, упорядочивающие однородный вид общественных. В качестве примера приведем приказ Минфина России от 9 августа 2005 г. № 102н, закрепляющий нормы в отношении правового положения комиссии - нормативный характер, а также нормы в отношении лиц, назначаемых на должность ее председателя - индивидуальный характер ${ }^{2}$.

Стоит отметить, что исследованию приказа, его места в системе правовых актов, посвящено немало работ [Бошно, Пытикова, 2005; Строкова, 2007; Артамонова, Намм, 2017], анализ которых позволил нам выделить следующие специфические особенности приказа: отражает волю управомоченного органа, единолично принимающего решение о его принятии; может выражаться в письменной и устной форме; закрепляет правила, обязательные к соблюдению конкретными субъектами; является подзаконным актом; издается только с учетом установленных полномочий и в соответствии с компетенцией органа управления; принимается в целях упорядочивания отношений, находящихся вне правовой сферы.

Таким образом, приказ является нормативным актом и издается в том случае, когда появляется необходимость решения неурегулированных действующим законодательством вопросов, т.е. происходит конкретизация нормативных правовых актов, изданных вышестоящими органами государственной власти (определяется порядок совершения определенных действий (процедур), срок исполнения определенных действий и т.д.).

\section{Характерные особенности постановления, правил, инструкций и положений}

На сегодняшний день постановление как вид правовых актов органов исполнительной власти практически не встречаются. Объяснение этому можно найти, учитывая саму природу понятия «постановление», под которым понимается коллективное решение, резолюция [Кузнецов, 1998]. Согласимся с мнением В.Ф. Ломакиной, которая указывает, что постановления в большей степени свойственны актам, принимаемым Правительством РФ [Ломакина, 2017]. Действительно, Правительство Российской Федерации представляет собой коллегиальный орган, где решения принимаются с участием каждого из его членов $^{3}$, тогда как органы исполнительной власти издают правовые акты на основании одностороннего властного волеизъявления [Смирнова, 2005]. Кроме того, в структуру исполнительных органов государственной власти входят и органы субъектов, в которых односторонний характер выражается в следующем: во-первых, решение вопроса о возникновении предполагаемых правоотношений стоит за волей одного субъекта - органа исполнительной власти субъекта Российской Федерации; во-вторых - для их принятия и отмены не требуется согласия тех, на кого они распространяют свое действие.

${ }^{1}$ Указ Президента РФ от 10.11.2007 № 1495 «Об утверждении общевоинских уставов Вооруженных Сил Российской Федерации» (ред. от 21.02.2019). С3 РФ. 2007. № 47 (1 ч.). Ст. 5749; С3 РФ. 2019. № 8. Ст. 761.

2 Приказ Минфина РФ от 09.08.2005 № 102н «О создании Межведомственной комиссии по координации взаимодействия Минфина России и ФНС России в налоговой сфере» (с изм. от 17.07.2006). Экономика и жизнь. 2005. № 37.

${ }^{3}$ Федеральный конституционный закон от 17.12.1997 № 2-ФКЗ «О Правительстве Российской Федерации» (ред. от 28.12.2016). СЗ РФ. 1997. № 51. Ст. 5712; 2017. № 1 (Часть I). Ст. 3. 
Исходя из сказанного, отличительным признаком постановления от приказа, впрочем, как и от других правовых актов, является его коллегиальный характер, тогда как остальные документы принимаются единолично.

Следующими правовыми актами являются правила и инструкции. Правила представляют собой подзаконные правовые акты, «устанавливающее определенный порядок» [Кузнецов, 1998]. Так, МЧС Российской Федерации утверждаются правила пожарной охраны предприятий, отражающие последовательность и содержание действий субъектов $^{1}$. Среди действующих правовых актов можно встретить и документы под названием «Порядок», который является синонимом правил, в этой связи часть таких документов представлены следующим образом².

Правила (порядок) как форма акта распространены достаточно широко. Однако в своем большинстве они утверждаются другими актами: постановлениями ${ }^{3}$, приказами ${ }^{4}$, распоряжениями ${ }^{5}$. В качестве самостоятельного документа их встретить практические невозможно (в основном они утратили силу).

Инструкция по своему назначению описывает поведение субъектов по поводу предметов материального мира: например, инструкция о порядке и способах выполнения какой-либо работы, пользования машиной, прибором и т.п. [Кузнецов, 1998].

Как и правила, инструкции в большинстве своем идут в сочетании с другими актами - утверждаются приказами ${ }^{6}$, что уже прочно вошло в процесс правотворчества. Однако можно привести примеры и самодостаточных инструкций ${ }^{7}$.

Таким образом, правила и инструкции - это разновидности правового акта, издаваемые в целях разъяснения реализации норм вышестоящего документа в части выполнения определенных действий, операции.

Следующим правовым актом выступает положение, которое применяется в целях детальной регламентации правового статуса, организации, порядка деятельности определенных государственных органов, организаций и учреждений или системы однородных органов, учреждений, организаций [Кузнецов, 1998]. В основе положений стоит решение узкоспециальных вопросов ${ }^{8}$. Чаще положения утверждаются приказами ${ }^{9}$.

Таким образом, отличие приказа от правил, инструкций и положений не вызывает сомнений. Проведенный анализ правотворческой практики в части их использования поз-

${ }^{1}$ Приказ МЧС России от 03.07.2015 № 341 «Об утверждении свода правил «Пожарная охрана предприятий. Общие требования» (вместе с «СП 232.1311500.2015. Свод правил...»). СПС «Консультант Плюс».

${ }^{2}$ Приказ МЧС России от 12.03.2018 № 99 «Об утверждении Порядка регистрации аварийноспасательных служб, аварийно-спасательных формирований». СПС «Консультант Плюс».

${ }^{3}$ Постановление Минтруда РФ от 21.07.1997 № 41 «Об утверждении Положения о порядке оказания гражданам содействия в трудоустройстве в другой местности». СПС «Консультант Плюс».

${ }^{4}$ Приказ Минспорта России от 23.03.2020 № 237 «Об утверждении правил вида спорта «американский футбол». СПС «Консультант Плюс».

${ }^{5}$ Распоряжение Госкомимущества РФ от 30.12.1994 № 2937-р «Об установлении порядка приватизации пакетов акций, находящихся в собственности РФ, предприятий, включенных в состав Федеральной контрактной системы». СПС «Консультан Плюс».

${ }^{6}$ Приказ Минобрнауки России от 26.06.2019 № 439 «Об утверждении Инструкции о мерах пожарной безопасности в Министерстве науки и высшего образования Российской Федерации». СПС «Консультант Плюс».

${ }^{7}$ Инструкция Банка России от 30.05.2014 № 153-И «Об открытии и закрытии банковских счетов, счетов по вкладам (депозитам), депозитных счетов» (ред. от 24.12.2018). СПС «Консультант Плюс».

${ }^{8}$ Положение Банка России от 22.09.2017 № 602-П (ред. от 23.03.2020) «О правилах подготовки нормативных актов Банка России». Вестник Банка России. 2017. № 84; 2020. № 25.

${ }^{9}$ Приказ Казначейства России от 22.01.2013 № 5 «Об утверждении Типового положения о юридическом отделе территориального органа Федерального казначейства» (ред. от 18.12.2019). СПС «Консультант Плюс». 
воляет сделать вывод о неверном понимании формы этих документа как несамостоятельной, производной правовой конструкции, которые в большинстве своем утверждаются иными формами (приказами, распоряжениями). Сказанное свидетельствует об избыточности двух форм.

\section{Разграничение приказа и распоряжения как однородных категорий}

Иначе обстоят дела с разграничением приказа и распоряжения. Сложность состоит в том, что данные категории достаточно часто рассматриваются как синонимы. Подобные позиции отражаются как в справочной литературе [Ожегов, 2008], так и в ряде правовых документов ${ }^{1}$ и научных исследованиях [Соломоненко, 1999]. В.Я. Григенча придерживается мнения, что достаточно установления дефиниции «приказ», закрепив в соответствующем постановлении за ним определение и иных актов управления [Григенч, 1997].

В научных трудах распоряжение характеризуется как вид подзаконного акта управления, который издается с учетом компетенции органа власти или управления, обязателен для субъектов, в отношении которых принято [Ломакина, 2015]. Исходя из определения в качестве его признаков можно выделить подзаконный характер; издается в рамках компетенции органом государственной власти; его предписания обязательны для исполнения; принимается для упорядочивания определенной сферы общественных отношений.

Таким образом, приказ и распоряжение являются достаточно похожими формами правовых актов, вместе с тем считаем важным выделить и их отличительные черты. В частности, разграничение категорий «приказ» и «распоряжение» можно выделить исходя из анализа правовых документов Министерства внутренних дел РФ, где закреплено, что приказ издается по наиболее важным вопросам функционирования органов внутренних дел Российской Федерации, включая определение их задач и функций, правовое регулирование различных направлений оперативно-служебной деятельности, прохождения службы в органах внутренних дел ${ }^{2}$. Тогда как распоряжения - документ, издаваемый по вопросам оперативно-служебной деятельности органов внутренних дел, который имеет организационно-распорядительный характер ${ }^{3}$. Сказанное свидетельствует о содержательном различии приказа и распоряжения, где приказ отражает регулирование наиболее важных вопросов.

Отличительными признаками приказа и распоряжения выступают иерархичность издание приказа является характерной особенностью рабочих правоотношений между руководителем и его сотрудником; и служебность - приказ должен быть отдан по службе и в рамках служебных полномочий [Девятко, 2004], тогда как распоряжение может быть отдано и без учета указанных признаков.

Например, приказ и распоряжение сотрудника полиции будут являться обязательными для исполнения любым гражданином. Однако в отличие от полицейского, если гражданин не является сотрудником органов внутренних дел, то он не находится в слу-

${ }^{1}$ Приказ Ространснадзора от 29.03.2019 № ВБ-261фс «Об утверждении Регламента Федеральной службы по надзору в сфере транспорта». СПС «Консультант Плюс».

${ }^{2}$ Приказ МВД России от 27.06.2003 № 484«Об утверждении Правил подготовки нормативных правовых актов в центральном аппарате МВД России» (ред. от 18.02.2019). СПС «Консультант Плюс».

${ }^{3}$ Приказ МВД России от 20.06.2012 № 615 «Об утверждении Инструкции по делопроизводству в ОВД РФ Министерства внутренних дел Российской Федерации». СПС «Консультант Плюс». 
жебном или профессиональном подчинении у полицейского, тогда как сотрудник является подчиненным лицом своему начальнику и должен выполнять его приказы.

Таким образом, приказ и распоряжение, хотя и однородные, но не тождественные между собой понятия.

\section{Заключение}

Считаем, что нынешняя ситуация, связанная с отсутствием конкретных, законодательно установленных понятий, признаков каждой из форм правовых актов - приказа, постановления, правил, инструкций, положений и распоряжений, ведет к возникновению множества вопросов в части их применения - неоднозначному толкованию сущности и форм официально-документального выражения правовых актов, проблемам отграничения их от других официальных документов, что в итоге отрицательно воздействует на весь механизм управления. Справедливо отмечено, что важно направить усилия для создания и регламентации общих требований в отношении каждой из разновидностей правовых актов федеральных органов исполнительной власти. Подобные требования должны отражать в первую очередь содержание, во-вторых - форму, и в-третьих - процедуру принятия актов. Кроме того, необходимо отойти от действующей практики по использованию двойной формы нормативного правового акта (когда правила, инструкции утверждаются приказами) и дать разъяснения по всем формам актов.

\section{Список источников}

1. Кузнецова С.А. 1998. Большой толковый словарь русского языка. Первое издание. СПб: Норинт, $1534 \mathrm{c}$.

2. Ожегов С.И. 2008. Словарь русского языка. Москва: Локид-Пресс: 910 с.

\section{Список литературы}

1. Артамонова С.Н., Намм Г.А. 2017. К вопросу о соотношении понятий «приказ» и «распоряжение» в институтах государственной гражданской службы и военной службы и их месте в системе правовых актов Российской Федерации. Вестник военного права, 2: 56-61.

2. Бошно С.В., Пытикова Т.А. 2005. Приказ: нормативный или правоприменительный акт? Юрист. 10: 10-12.

3. Ваньков А.В., Сумачев А.В. 2018. Правовой акт: понятие и общая характеристика. Вестник Уральского финансово-юридического института. 3: 3-6.

4. Вдовин М.А., Гибадуллина К.А. 2018. Индивидуальные правовые акты: понятие, признаки и требования. Аллея науки. 5(2): 801-803.

5. Григенча В.Я. 1997. Уголовно-правовые проблемы исполнения приказа: Автореф. дис.... канд. юрид. наук. Екатеринбург, 24 с.

6. Девятко А.Ю. 2004. Исполнение приказа или распоряжения военнослужащим как обстоятельство, исключающее преступность деяния: Автореф. дис.... канд. юрид. наук. М., 26 с.

7. Ломакина В.Ф. 2015. Правовая природа актов государственного управления. Труды Института государства и права Российской академии наук, 4: 36-55.

8. Ломакина В.Ф. 2017. Административные правовые акты в механизме государственного управления. В кн.: Формы и методы государственного управления в современных условиях развития. М., Прометей: 393 с.

9. Смирнова А.А. 2005. Юридическая природа нормативно правовых актов исполнительных органов государственной власти субъектов Российской Федерации. Право и политика. 9: 84-89.

10. Соломоненко И.Г. 1999. Исполнение приказа и его уголовно-правовое значение (в деятельности органов внутренних дел): Автореф. дис.... канд. юрид. наук. М., 24 с.

11. Строкова О.Г. 2007. Приказ как особая разновидность правового акта: вопросы теории и практики: Автореф. дисс. ... канд. юрид. наук. Саратов, 25 с. 
12. Талаев И.В. 2019. Понятие «приказ» в законодательстве и уголовно-правовой доктрине России. Российское правосудие. 12: 90-94.

\section{References}

1. Artamonova S.N., Namm G.A. 2017. K voprosu o sootnoshenii ponyatij «prikaz» i «rasporyazhenie» v institutah gosudarstvennoj grazhdanskoj sluzhby i voennoj sluzhby i ih meste $\mathrm{v}$ sisteme pravovyh aktov Rossijskoj Federacii [On the question of the relationship between the concepts of "order" and" order " in the institutions of state civil service and military service and their place in the system of legal acts of the Russian Federation]. Vestnik voennogo prava, 2: 56-61.

2. Boshno S.V., Pytikova T.A. 2005. Prikaz: normativnyj ili pravoprimenitel'nyj akt? [Order: regulatory or law enforcement act] YUrist, 10: 10-12.

3. Van'kov A.V., Sumachev A.V. 2018. Pravovoj akt: ponyatie i obshchaya harakteristika [Legal act: concept and General characteristics]. Vestnik Ural'skogo finansovo-yuridicheskogo instituta, 3: 3-6.

4. Vdovin M.A., Gibadullina K.A. 2018. Individual'nye pravovye akty: ponyatie, priznaki i trebovaniya [Individual legal acts: concept, features and requirements]. Alleya nauki, 5(2): 801-803.

5. Grigencha V.YA. 1997. Ugolovno-pravovye problemy ispolneniya prikaza [Criminal-legal problems of execution of an orde]: Avtoref. dis.... kand. yurid. nauk. Ekaterinburg, 24 p.

6. Devyatko A.YU. 2004. Ispolnenie prikaza ili rasporyazheniya voennosluzhashchim kak obstoyatel'stvo, isklyuchayushchee prestupnost' deyaniya [Execution of an order or instruction by a military man as a circumstance that precludes criminality of an act]: Avtoref. dis.... kand. yurid. nauk. M., 26 p.

7. Lomakina V.F. 2015. Pravovaya priroda aktov gosudarstvennogo upravleniya [Legal nature of public administration acts]. Trudy Instituta gosudarstva i prava Rossijskoj akademii nauk, 4: 36-55.

8. Lomakina V.F. 2017. Administrativnye pravovye akty v mekhanizme gosudarstvennogo upravleniya [Administrative legal acts in the mechanism of public administration]. In: Formy i metody gosudarstvennogo upravleniya $\mathrm{v}$ sovremennyh usloviyah razvitiya [Forms and methods of public administration in modern conditions of development]. M., Pabl. Prometej: 393 p.

9. Smirnova A.A. 2005. YUridicheskaya priroda normativno pravovyh aktov ispolnitel'nyh organov gosudarstvennoj vlasti sub"ektov Rossijskoj Federacii [Legal nature of normative legal acts of Executive bodies of state power of the subjects of the Russian Federation]. Pravo i politika, 9: 84-89.

10. Solomonenko I.G. 1999. Ispolnenie prikaza i ego ugolovno-pravovoe znachenie (v deyatel'nosti organov vnutrennih del) [Execution of the order and its criminal-legal significance (in the activities of internal Affairs bodies)]: Avtoref. dis.... kand. yurid. nauk. M., 24 p.

11. Strokova O.G. 2007. Prikaz kak osobaya raznovidnost' pravovogo akta: voprosy teorii i praktiki [An order as a special type of legal act: questions of theory and practice: author's abstract]: Avtoref. diss. ... kand. yurid. nauk. Saratov. 25 p.

12. Talaev I.V. 2019. Ponyatie «prikaz» v zakonodatel'stve i ugolovno-pravovoj doktrine Rossii [The concept of "order" in the legislation and criminal law doctrine of Russia]. Rossijskoe pravosudie, 12: 90-94.

\section{ИНФОРМАЦИЯ ОБ АВТОРЕ}

Чернышев Андрей Викторович, соискатель кафедры теории государства и права ФГБОУ ВО «Саратовская государственная юридическая академия», Саратов, Россия

\section{INFORMATION ABOUT THE AUTHOR}

Andrey V. Chernyshev, candidate of the Department of State Theory and Law of FSBOU VO "Saratov State Law Academy," Saratov, Russia 